\title{
Sulfate Radical Oxidation of Aromatic Contaminants: A Detailed Assessment of Density Functional Theory and High-Level Quantum Chemical Methods
}

\author{
Sangavi Pari, ${ }^{1}$ Inger A. Wang, ${ }^{1, a}$ Haizhou Liu ${ }^{1 *}$ and Bryan M. Wong ${ }^{1,2 *}$ \\ ${ }^{1}$ Department of Chemical \& Environmental Engineering, University of California-Riverside, \\ Riverside, California, USA \\ ${ }^{2}$ Materials Science \& Engineering Program, University of California-Riverside, Riverside, \\ California, USA \\ ${ }^{a}$ Currently at Pennsylvania State University, University Park, Pennsylvania, USA \\ * Corresponding authors: Haizhou Liu: haizhou@engr.ucr.edu, tel: (951) 827-2076, fax (951) 827-5696 \\ and Bryan M. Wong: bryan.wong@ucr.edu, tel: (951) 827-2163, fax (951) 827-5696, website: http://www.bmwong-group.com
}

Submitted to Environmental Sciences: Processes \& Impacts 


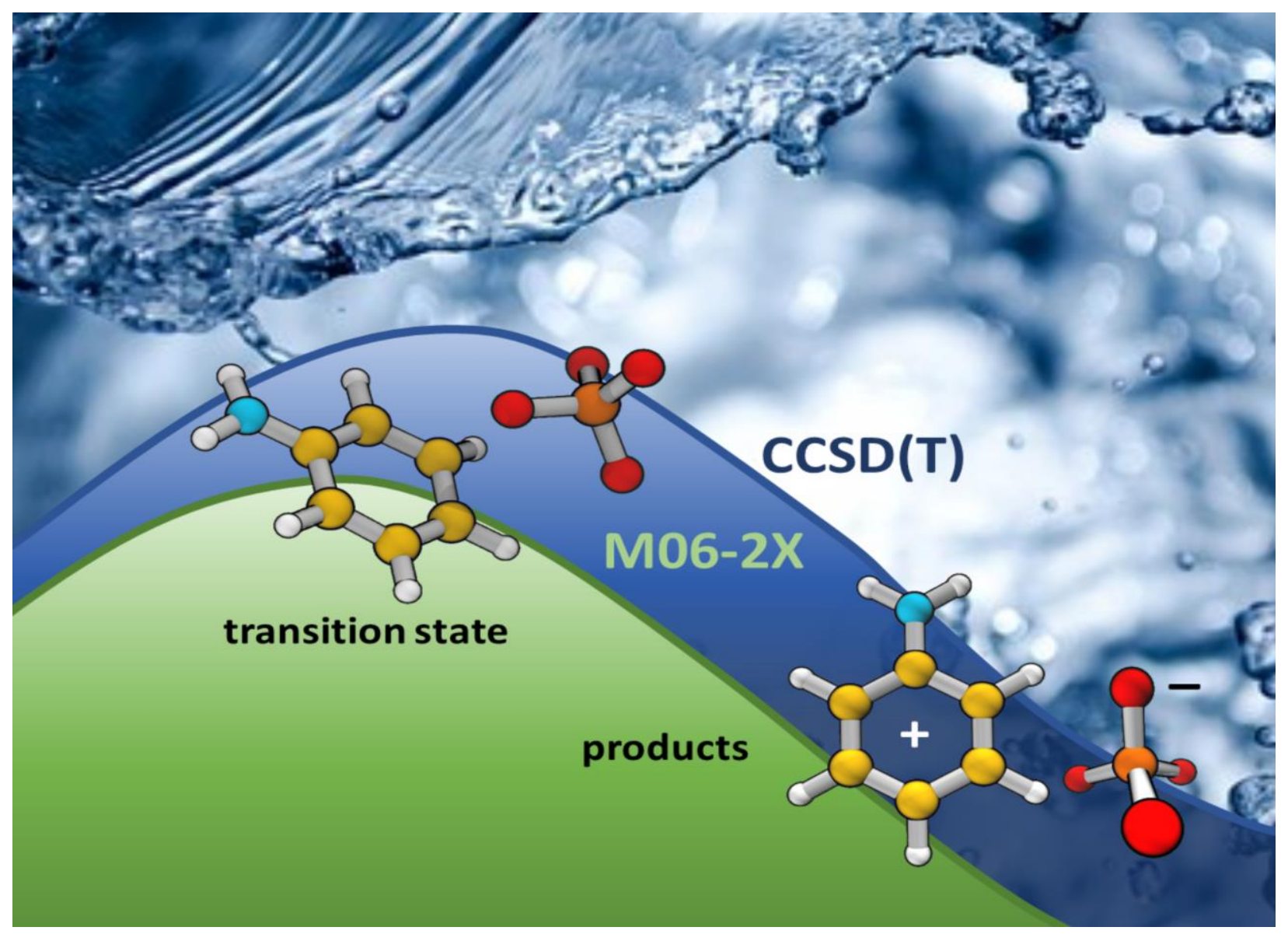

TOC Figure 


\begin{abstract}
Advanced oxidation processes that utilize highly oxidative radicals are widely used in water reuse treatment. In recent years, the application of sulfate radical $\left(\mathrm{SO}_{4}{ }^{-}\right)$as a promising oxidant for water treatment has gained increasing attention. To understand the efficiency of $\mathrm{SO}_{4}{ }^{-}$in the degradation of organic contaminants in wastewater effluent, it is important to be able to predict the reaction kinetics of various $\mathrm{SO}_{4}{ }^{-}$-driven oxidation reactions. In this study, we utilize density functional theory (DFT) and high-level wavefunction-based methods (including computationally-intensive coupled cluster methods), to explore the activation energies and kinetic rates of $\mathrm{SO}_{4}{ }^{\circ-}$-driven oxidation reactions on a series of benzene-derived contaminants. These high-level calculations encompassed a wide set of reactions including 110 forward/reverse reactions and 5 different computational methods in total. Based on the high-level coupled-cluster quantum calculations, we find that the popular M06-2X DFT functional is significantly more accurate for $\mathrm{HO}^{-}$additions than for $\mathrm{SO}_{4}{ }^{*-}$ reactions. Most importantly, we highlight some of the limitations and deficiencies of other computational methods, and we recommend the use of high-level quantum calculations to spot-check environmental chemistry reactions that may lie outside the training set of the M06-2X functional, particularly for water oxidation reactions that involve $\mathrm{SO}_{4}{ }^{-}$and other inorganic species.
\end{abstract}




\section{Introduction}

Water scarcity has become a global crisis. This situation is exacerbated - and will continue to be dominated - by the global shrinkage of surface water sources, notably sharp decreases caused by extreme climate conditions. ${ }^{1,2}$ Municipal wastewater reuse offers the potential to significantly increase the nation's total available water resources. Approximately 12 billion gallons of municipal wastewater effluent are discharged each day in the U.S., which is equivalent to $27 \%$ of the total public water supply. ${ }^{3}$ However, only about $10 \%$ of the wastewater effluent is actively reused nationwide. ${ }^{3}$ One major challenge to recycling is the development of efficient and cost-effective purification processes. Wastewater effluent is widely compromised by sewage produced from growing populations, industries and agriculture. Trace organic chemicals including petroleum hydrocarbons, pharmaceuticals, personal care products, and industrial solvents are often present in the effluent. ${ }^{4-13}$

To minimize the presence of trace organic chemicals, different advanced oxidation processes (AOPs) have been employed. ${ }^{14-19}$ The most widely applied approach is based on the photolysis of hydrogen peroxide $\left(\mathrm{H}_{2} \mathrm{O}_{2}\right)$ to produce hydroxyl radical (HO'). In recent years, sulfate radical $\left(\mathrm{SO}_{4}{ }^{-}\right)$has garnered much attention as an alternative oxidant for $\mathrm{AOP} .{ }^{20-22}$ In these processes, $\mathrm{SO}_{4}{ }^{--}$is typically generated via UV photolysis of persulfate $\left(\mathrm{S}_{2} \mathrm{O}_{8}{ }^{2-}\right)$ for water reuse applications. ${ }^{23-26} \mathrm{SO}_{4}^{--}$has a similar oxidizing power to $\mathrm{HO}^{\bullet}$, yet possessing selectively higher reaction rates with electron-rich contaminants that are typically observed in wastewater effluent. ${ }^{27-}$ ${ }^{30}$ Due to a higher quantum yield, the rate of $\mathrm{S}_{2} \mathrm{O}_{8}{ }^{2-}$ photolysis is $40 \%$ higher than that of $\mathrm{H}_{2} \mathrm{O}_{2}$ under UV irradiation at $254 \mathrm{~nm}$ (a typical wavelength used in UV lamps). ${ }^{31}$ Furthermore, the scavenging effect of $\mathrm{S}_{2} \mathrm{O}_{8}{ }^{2-}$ on $\mathrm{SO}_{4}{ }^{-}$is two orders of magnitude lower than the scavenging effect 
of $\mathrm{H}_{2} \mathrm{O}_{2}$ on $\mathrm{HO}^{*},{ }^{32,33}$ which leads to a higher yield of $\mathrm{SO}_{4}{ }^{-}$- from $\mathrm{S}_{2} \mathrm{O}_{8}{ }^{2-}$ than that of $\mathrm{HO}^{-}$from $\mathrm{H}_{2} \mathrm{O}_{2}$. These chemical features make $\mathrm{SO}_{4}{ }^{-}$-based $\mathrm{AOP}$ an attractive option for water reuse.

Considering these prospective applications of $\mathrm{SO}_{4}{ }^{--}$-based oxidation processes for water reuse, it is important to predict the reaction kinetics of $\mathrm{SO}_{4}{ }^{--}$-driven oxidation reactions with organic contaminants that are present in wastewater effluent. Although some of the radical-driven rate constants can be measured using experimental techniques, e.g., electron pulse radiolysis and $\gamma$ radiation, ${ }^{34,35}$ it is logistically unrealistic to experimentally measure the rates of every contaminant with short-lived radical species. In addition, the activation energies of $\mathrm{SO}_{4}{ }^{-*}$ with different benzene-derived contaminants are largely unknown, and understanding the activation energies in possible degradation pathways of organic contaminants on a fundamental level are required for predicting byproduct formation in $\mathrm{SO}_{4}{ }^{-}$based oxidative water treatment.

Recently, density functional theory (DFT) calculations have started to become commonplace as computational tools for predicting reaction mechanisms and activation energies in redox reactions of environmental significance. There has been recent work using quantum chemical techniques to estimate reaction barriers and thermodynamic relations in the degradation of trace organic contaminants, especially via the oxidation of $\mathrm{HO}^{\circ}$ or ozone $\left(\mathrm{O}_{3}\right) \cdot{ }^{36-41}$ Due to the complexity of the chemical species examined, these prior studies largely used popular computationally-efficient DFT methods to systematically explore and assess the reactivities of contaminants in the aqueous phase. However, most DFT methods are heavily parameterized against a training set of benchmark molecules, i.e., typically organic compounds containing only hydrogen, carbon, nitrogen, and oxygen. ${ }^{42-44}$ Specifically, these DFT methods were developed to minimize errors on a given training set of molecules; however, for systems and properties outside the training set, Burke and co-workers have demonstrated that these extrapolations can be prone 
to large and unpredictable deviations. ${ }^{45}$ As a result, additional high-level wavefunction based methods are essential to assess whether popular DFT methods are sufficiently accurate for modeling activation energies and thermochemistry, particularly for inorganic species outside typical DFT training sets, in environmental computational studies.

The purpose of this study is to assess the accuracy of popular DFT and high-level wavefunction-based methods in quantifying the activation energies of benzene-derived contaminants reacting with $\mathrm{SO}_{4}{ }^{\circ}$. Fig. 1 depicts the chemical structures of the various benzenederived organic contaminants, and Fig. 2 shows the two steps of oxidation reaction investigated in this work. Step 1 involves the addition of $\mathrm{SO}_{4}{ }^{-}{ }^{-}$to form a benzene-derivative cationic radical and the $\mathrm{SO}_{4}{ }^{2-}$ anion. The addition of hydroxide $\mathrm{OH}^{-}$to the benzene-derivative cation in Step 2 gives the final hydroxylated oxidation product. We examined a wide set of reactions (110 forward and reverse reactions, in total) using a variety of computational techniques including DFT, MP2/MP4 perturbation theory methods, and high-level coupled cluster CCSD/CCSD(T) approaches. Statistical analyses were carried out for all of these reactions to assess the strengths and limitations of each of the computational methods. We concluded with a discussion and assessment of the specific methods that provide the best accuracy in describing these specific reaction processes relevant to $\mathrm{SO}_{4}{ }^{-}$based oxidative water treatments. 
<smiles>Cc1ccccc1</smiles>

toluene<smiles>Cc1ccccc1C</smiles>

o-xylene<smiles>Cc1cccc(C)c1</smiles>

m-xylene<smiles>CCc1ccccc1</smiles>

ethylbenzene<smiles>Nc1ccccc1</smiles>

aniline<smiles>Cc1ccc(C)cc1</smiles>

p-xylene

Figure 1. Chemical structures of benzene-derived organic contaminants investigated in this work.

step 1

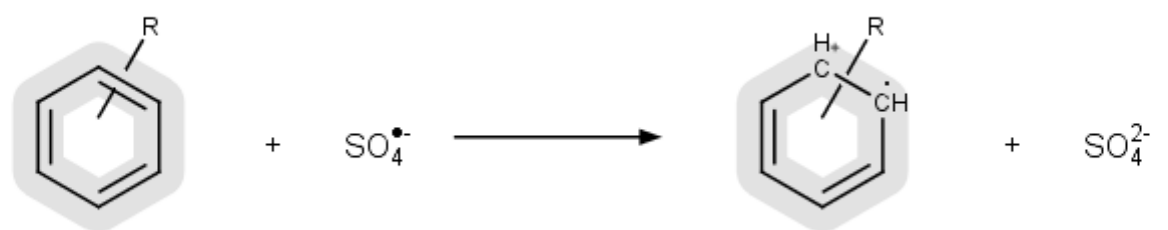

step 2

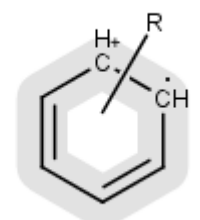

$+\mathrm{HO}^{\circ}$

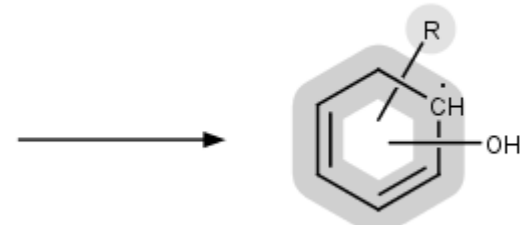

Figure 2. Reaction steps investigated in this work: Step 1 involves the addition of $\mathrm{SO}_{4}{ }^{-}$to form a benzene-derivative cation and the $\mathrm{SO}_{4}{ }^{2-}$ anion. The $R$ group represents the different functional groups depicted previously in Fig. 1. Step 1 involves the addition of $\mathrm{HO}^{-}$to the benzene-derivative cation that gives the final hydroxylated product. 


\section{Computational Methods}

For all of the chemical species investigated in this work, we benchmarked the performance of the highly-parametrized M06-2X DFT functional ${ }^{46}$ against the wavefunction-based MP2, ${ }^{47,48}$ MP4(SDQ), ${ }^{49}, 50$ CCSD, ${ }^{51,52}$ and $\operatorname{CCSD}(\mathrm{T})^{53}$ methods. The M06-2X exchange-correlation functional $^{46}$ includes $54 \%$ Hartree-Fock exchange and has been utilized to study a broad spectrum of chemical species and reactions. ${ }^{54-59}$ The MP2 $2^{47,48}$ and MP4(SDQ) $)^{49,50}$ wavefunction-based methods incorporate a Møller-Plesset correlation correction ${ }^{60}$ to the total energy based on perturbation theory truncated at second order and fourth order for MP2 ${ }^{47,} 48$ and MP4(SDQ), ${ }^{49,} 50$ respectively. The $\operatorname{CCSD}^{61,62}$ and $\operatorname{CCSD}(\mathrm{T})^{53}$ methods utilize a coupled cluster approach including both single and double excitations (and triple excitations for the $\operatorname{CCSD}(\mathrm{T})$ method) to obtain highly accurate total energies. The higher-level CCSD and CCSD(T) theoretical approaches typically provide extremely accurate energies and reaction rates, albeit at a high computational cost. In order to maintain a consistent comparison across the M06-2X, MP2, MP4(SDQ), CCSD, and CCSD(T) levels of theory, the same ground-state and transition-state geometries for all methods were used. Both the ground-state and transition-state geometries were obtained optimized at the M06-2X/6$311+\mathrm{G}(\mathrm{d}, \mathrm{p})$ level of theory, and all transition states were confirmed to be first-order saddle points by verifying the presence of a single imaginary harmonic frequency. It is worth mentioning that a complete characterization of a transition state geometry requires a full analysis of the intrinsic reaction coordinate (IRC); however, due to the large number of reactions considered in this study (110 forward/reverse reactions) and the immense computational expense of IRC calculations, we only characterized these transition states with a frequency analysis and reserved the more complete IRC calculations for a future study. For all of the chemical species and computational methods in this study, we utilized the conductor-like polarizable continuum model (PCM) devised by Tomasi 
and co-workers ${ }^{63-67}$ which creates a solute cavity via a set of overlapping spheres to calculate the solvent reaction field.

For all of the wavefunction-based methods (MP2, MP4(SDQ), CCSD, and CCSD(T)) in this study, the same $6-311+\mathrm{G}(\mathrm{d}, \mathrm{p})$ basis was also used to calculate total energies for both the ground- and transition-state geometries. Throughout this work we used the CCSD(T) energies as reference values to assess the quality for all of the various methods. We have previously found that the $\operatorname{CCSD}(\mathrm{T})$ method accurately reproduces experimental activation energies ${ }^{68,69}$ and electronic properties ${ }^{70}$ of various hydrocarbons. As an additional verification on the quality of the $\operatorname{CCSD}(\mathrm{T})$ benchmarks, we checked for possible deficiencies inherent to the single-reference coupled cluster approach. Specifically, for open-shell systems, Schaefer and co-workers ${ }^{71}$ proposed an open-shell "T1 diagnostic" to determine whether the single-reference-based CCSD procedure is appropriate or requires a higher-level multi-reference treatment. Based on their criterion, if the Euclidean norm of the $\mathrm{t} 1$ vector from an open-shell CCSD calculation is greater than 0.044 , a higher-level multireference method is necessary. We have computed the T1 diagnostic for all of the geometry-optimized chemical species in this work and found that none of the systems in this study required a multi-reference treatment of electron correlation (open-shell T1 diagnostic values were in the $0.026-0.039$ range), indicating that all of the chemical species in this study are accurately described by the coupled-cluster approach. All calculations were carried out with the Gaussian 09 package. ${ }^{72}$

\section{Results and Discussion}

Before proceeding to a detailed discussion of activation energies for the various reactions, we first carried out a series of two high-level benchmark calculations to assess (1) the robustness 
of the M06-2X optimized geometries and (2) the accuracy of the 6-311+G(d,p) basis set. Due to the computational complexity of these benchmarks, we only performed these calculations on the 1-aminophenol transition-state and final product, as shown in Fig. 3 (as a side note, these benchmark calculations were extremely computationally intensive, with the largest of these calculations taking up to 6 continuous days on $16 \times 2.3 \mathrm{GHz}$ AMD Opteron CPUs and over 230 GB of disk space on rapid-access solid state drive storage). To assess the robustness of the M062X optimized geometries, we calculated CCSD single-point energies on top of CCSD and M062X optimized geometries for the 1-aminophenol transition-state and final product. Fig. 3(a) shows that the difference in CCSD single-point energies obtained from the CCSD and M06-2X optimized geometries is negligible (less than $0.2 \mathrm{kcal} / \mathrm{mol}$ ), indicating that the M06-2X geometries used throughout this work are reliable. With the M06-2X optimized geometries verified, we next assessed the accuracy of the 6-311+G(d,p) basis set by comparing CCSD(T)/aug-cc-pvtz and $\operatorname{CCSD}(\mathrm{T}) / 6-311+\mathrm{G}(\mathrm{d}, \mathrm{p})$ single-point energies on top of the same M06-2X optimized geometries used in Fig. 3(a). Fig. 3(b) shows that the difference between the correlation-consistent aug-ccpvtz and the smaller 6-311+G(d,p) basis set is also relatively small (less than $0.65 \mathrm{kcal} / \mathrm{mol}$ ), indicating that the $6-311+\mathrm{G}(\mathrm{d}, \mathrm{p})$ basis set can be safely used for calculating the thermochemical properties for the numerous reactions (110 forward/reverse reactions) evaluated in this computational study. 
(a) Optimized Geometry Comparison

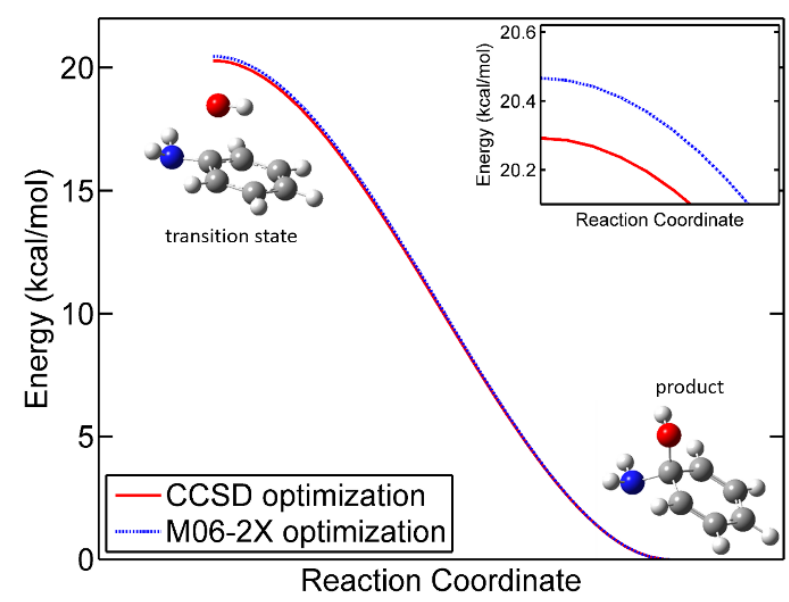

(b) Basis Set Comparison

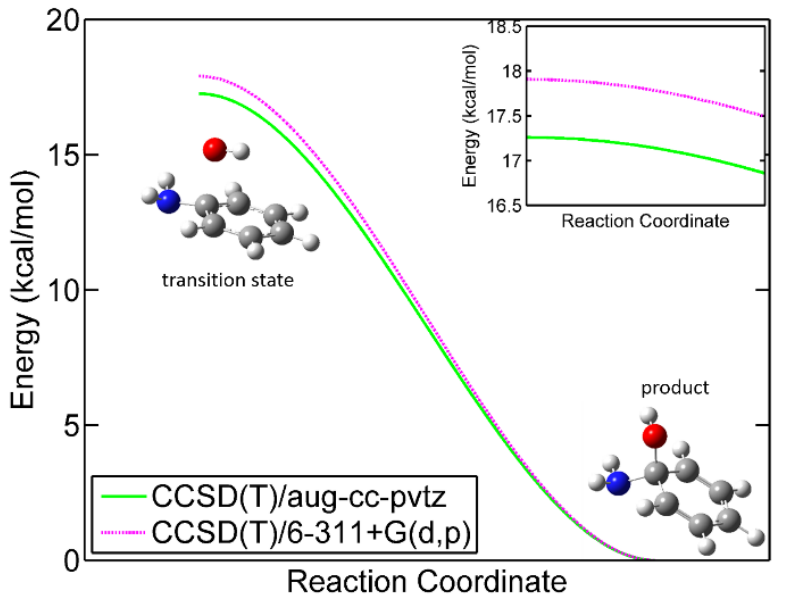

Figure 3. Comparison of (a) CCSD single-point energies on top of CCSD and M06-2X optimized geometries and (b) CCSD(T)/aug-cc-pvtz and CCSD(T)/6-311+G(d,p) single-point energies on top of M06-2X optimized geometries for 1-aminophenol. The insets in each of the figures show a magnified portion of the potential energy surface near the transition state, indicating a small energy difference among the various computational methods used in each of the figures.

With these benchmark tests validating our computational approach, we then examined the activation energies for the initial reaction step involving the addition of $\mathrm{SO}_{4}{ }^{-}$to the various benzene-derived contaminants. For each of the contaminant, there are multiple sites on the benzene ring that the $\mathrm{SO}_{4}{ }^{--}$radical can attach to in the transition state structure. As an example, Fig. 4 depicts the various transition state structures involved in the following reaction: toluene $+\mathrm{SO}_{4}{ }^{-}$ $\rightarrow$ toluene cation $+\mathrm{SO}_{4}{ }^{2-}$. We explored all of these possible transition-state geometries for toluene as well as for all the chemical species (25 transition states in total) depicted in Fig. 1. Using the $\operatorname{CCSD}(\mathrm{T})$ activation energies, $E_{a}$, as benchmarks, we performed a mean absolute error (MAE) analysis for both the forward and reverse activation energies involving $\mathrm{SO}_{4}{ }^{-}$and the various chemical species, which is summarized in Table 1. Fig. 5 depicts in more detail the general trends in the forward and reverse activation energies between the various quantum chemical methods. The diagonal line in all of these figures represents an ideal $100 \%$ agreement between the CCSD(T) 
energies and the other computational methods. It is important to mention that the $R^{2}$ values listed in Table 1 were obtained from a simple linear fit to the data points themselves and not calculated with respect to the diagonal lines shown in Fig. 5. From the results shown in Fig. 5, it is worth mentioning that the calculated forward activation energy in step 1 is larger than its reverse activation energy; however, the product of the forward reaction in step 1 (i.e., the benzene cation radical) can further react with $\mathrm{HO}^{-}$via the forward reaction in step 2 (Fig. 2). As discussed further in the paragraphs below, the forward activation energy in step 2 is lower than reverse activation energy in step 1. As a result, the rate-limiting step is the forward reaction involving a benzenederived compound and $\mathrm{SO}_{4}{ }^{\circ}$, and once this energy barrier is overcome, the benzene-derivative cation cation radical will further react with HO- to generate the hydroxylated product.

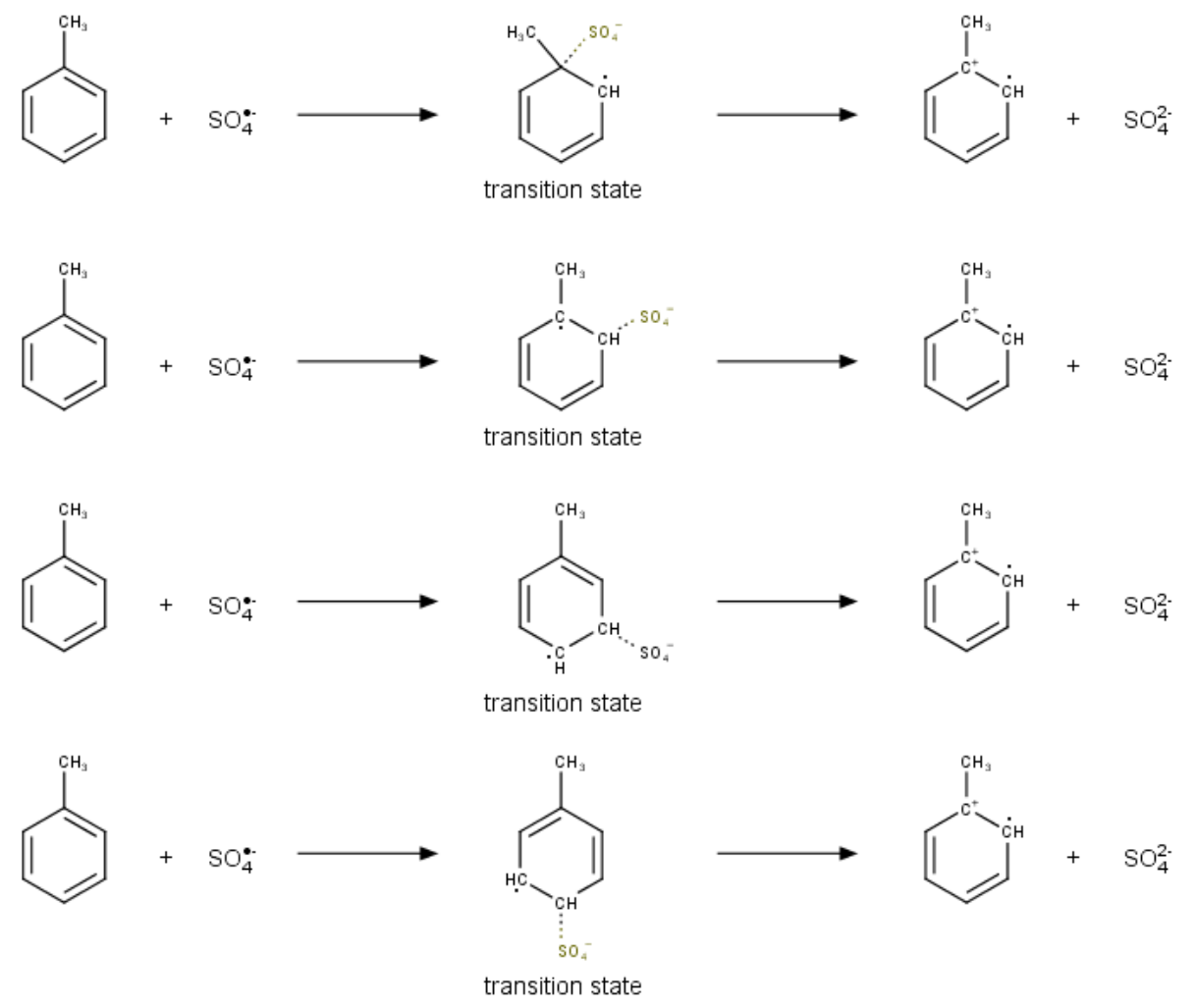

Figure 4. Reactants, transition states, and products for the first reaction step involving addition of $\mathrm{SO}_{4}{ }^{\circ-}$ to toluene. 
Table 1. Mean absolute error (MAE) with respect to $\operatorname{CCSD}(\mathrm{T})$ benchmarks and $R^{2}$ fit values for various activation energies (Ea) computed with the M06-2X, MP2, MP4(SDQ), and CCSD methods.

\begin{tabular}{|c|c|c|c|c|c|c|c|c|}
\hline & \multicolumn{2}{|c|}{ M06-2X } & \multicolumn{2}{|c|}{ MP2 } & \multicolumn{2}{|c|}{ MP4(SDQ) } & \multicolumn{2}{|c|}{ CCSD } \\
\hline & $\underset{(\mathbf{k c a l} / \mathbf{m o l})}{\operatorname{MAE}}$ & $R^{2}$ & $\underset{\text { (kcal/mol) }}{\operatorname{MAE}}$ & $R^{2}$ & $\underset{\text { (kcal/mol) }}{\text { MAE }}$ & $R^{2}$ & $\underset{(\mathbf{k c a l} / \mathbf{m o l})}{\operatorname{MAE}}$ & $R^{2}$ \\
\hline $\begin{array}{l}\text { Forward } \mathrm{E}_{\mathrm{a}} \\
\text { for } \mathrm{SO}_{4}^{-} \\
\text {addition }\end{array}$ & 3.35 & 0.95 & 19.34 & 0.69 & 8.23 & 0.83 & 1.02 & 0.99 \\
\hline $\begin{array}{l}\text { Reverse } \mathrm{E}_{\mathrm{a}} \\
\text { for } \mathrm{SO}_{4}^{--} \\
\text {addition }\end{array}$ & 2.00 & 0.99 & 15.37 & 0.38 & 10.11 & 0.86 & 4.20 & 1.00 \\
\hline $\begin{array}{l}\text { Forward } \mathrm{E}_{\mathrm{a}} \\
\text { for } \mathrm{HO}^{-} \\
\text {addition }\end{array}$ & 0.88 & 0.99 & 17.51 & 0.83 & 9.56 & 0.96 & 1.69 & 1.00 \\
\hline $\begin{array}{l}\text { Reverse } \mathrm{E}_{\mathrm{a}} \\
\text { for } \mathrm{HO}^{-} \\
\text {addition }\end{array}$ & 0.49 & 0.88 & 8.26 & 0.81 & 6.34 & 0.91 & 2.27 & 0.99 \\
\hline
\end{tabular}

(a) Forward $\mathrm{E}_{\mathrm{a}}$ for $\mathrm{SO}_{4}{ }^{-}$Addition

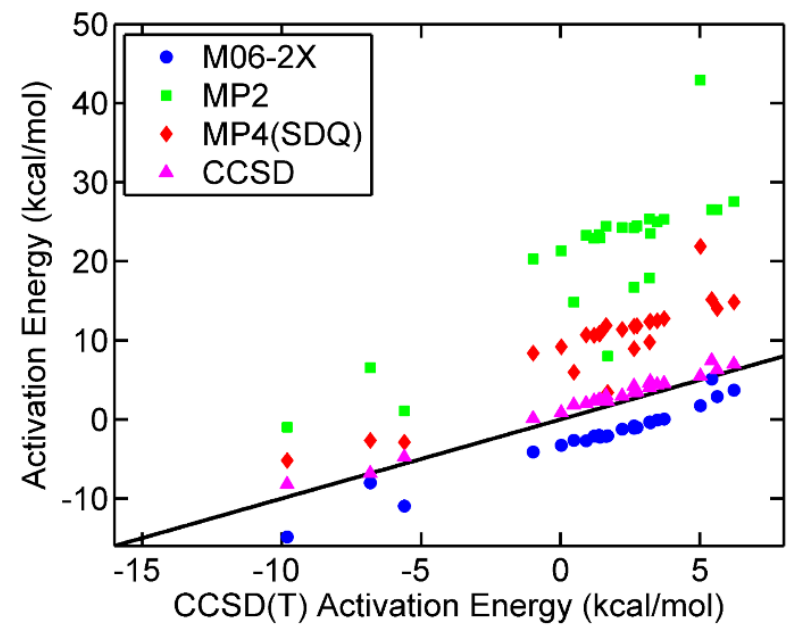

(b) Reverse $\mathrm{E}_{\mathrm{a}}$ for $\mathrm{SO}_{4}{ }^{\cdot-}$ Addition

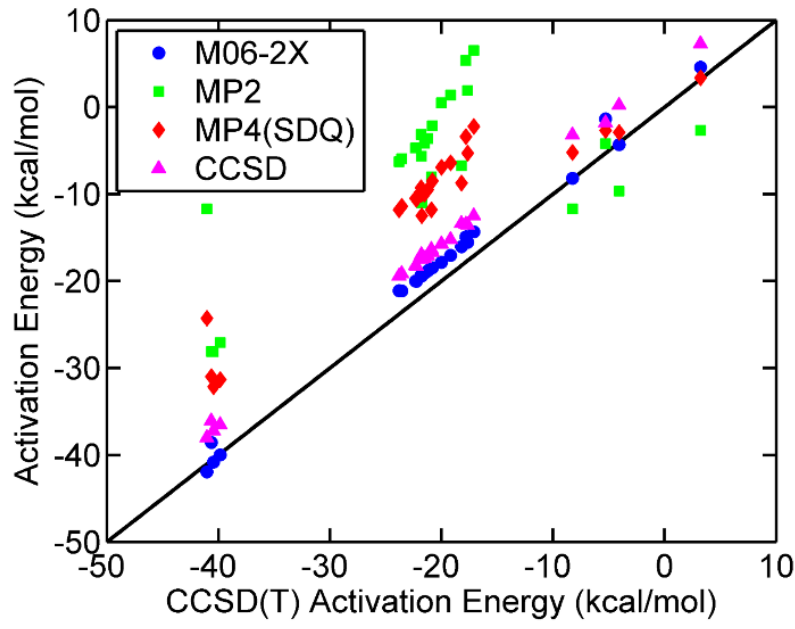

Figure 5. Predicted activation energies of the (a) forward and (b) reverse reactions of various benzene derivatives reacting with $\mathrm{SO}_{4}{ }^{*}$. The diagonal line in each figure represents a perfect match to the benchmark $\operatorname{CCSD}(\mathrm{T})$ activation energies. 
Both Table 1 and Fig. 5 show that the CCSD calculations $(\mathrm{MAE}=1.02 \mathrm{kcal} / \mathrm{mol})$ are in excellent agreement with the $\mathrm{CCSD}(\mathrm{T})$ benchmarks for the forward activation energy for the $\mathrm{SO}_{4}{ }^{\circ}$ addition. The M06-2X calculations have errors that are quite higher $(\mathrm{MAE}=3.35 \mathrm{kcal} / \mathrm{mol})$, followed by the MP4(SDQ) and MP2 methods which have even larger MAEs of 8.23 and 19.34 $\mathrm{kcal} / \mathrm{mol}$, respectively. Upon examining the reverse activation energy for the $\mathrm{SO}_{4}{ }^{-}$addition, we surprisingly find that the M06-2X functional significantly outperforms the CCSD method by a factor of 2 with respect to the total MAE. Again, the MP4(SDQ) and MP2 methods incur larger errors compared to either the CCSD or M06-2X calculations for the reverse activation energy for the $\mathrm{SO}_{4}{ }^{--}$addition. We also note that the $\mathrm{CCSD}$ and $\mathrm{M} 06-2 \mathrm{X}$ calculations exhibit a high degree of statistical correlation $\left(R^{2}=0.95-1.00\right)$ for both the forward and reverse activation energy for the $\mathrm{SO}_{4}{ }^{-}$addition, indicating that the errors in each of these computational methods is systematic rather than random.

We next examined the activation energies for the second reaction step involving the addition of $\mathrm{HO}^{-}$to the various benzene-derived cation radicals. As before, for each of the benzene cation radical, there are multiple sites on the benzene ring that the $\mathrm{HO}^{-}$molecule can attach to. As a particular example, Fig. 6 depicts the various products involved in the addition of $\mathrm{HO}^{-}$to the toluene cation. Again, we explored all of these possible transition-state geometries for toluene as well as for all the chemical species (30 transition states in total) depicted in Fig. 1, yielding the various products shown in Fig. 6. A mean absolute error (MAE) analysis was carried out for both the forward and reverse activation energies for all of these resulting products using the $\operatorname{CCSD}(\mathrm{T})$ activation energies as benchmarks. Table 1 and Fig. 7 summarize and depict the general trends in the forward and reverse activation energies between the various quantum chemical methods. 

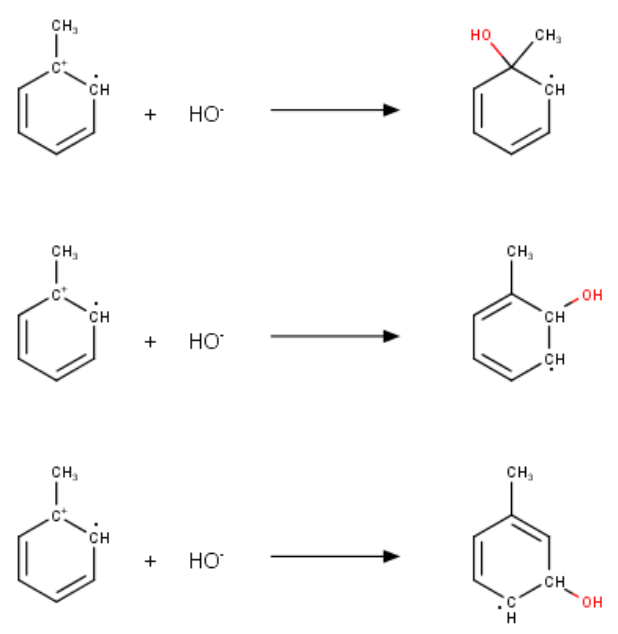<smiles>CC1=CCC(O)C=C1</smiles>

Figure 6. Reactants and products for the second reaction step involving addition of $\mathrm{HO}^{-}$to toluene.
toluene
derivatives
ethylbenzene
derivatives
o-xylene
derivatives
$m$-xylene
derivatives
p-xylene
aniline
derivatives
nitrobenzene<smiles>CC1C=CC=CC1(C)O</smiles><smiles>CC1=CC=CC(C)(O)C1</smiles><smiles>CC1=CCC(C)(O)C=C1</smiles><smiles>NC1(O)C=CC=CC1</smiles><smiles>CC1=CC=CCC1O</smiles><smiles>CCC1=CC=CCC1O</smiles><smiles>C[Y]1cccc(C)c1N</smiles>

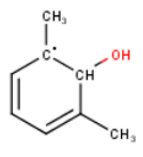<smiles>Cc1cccc(O)c1</smiles><smiles></smiles>

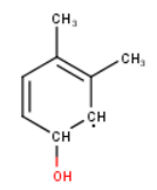

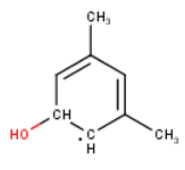<smiles>CC1=CN(C)[In](C)C=C1</smiles><smiles>CC1=CC=C[In]C1C</smiles><smiles>CC1=CI(C)P(C)C=C1</smiles><smiles>Cc1cc[n+](C)c(C)c1</smiles><smiles>C[C+]1C=CC(C)C=C1</smiles><smiles>CC1(C)C=CCC[CH-]1</smiles><smiles>[CH2]C1=CC=[In]C1[Hg]</smiles><smiles>CCC1=C[C](C)NC=C1</smiles>

Figure 7. All possible products resulting from the reaction of various hydroxylated oxidation products from oxidation of benzene derivatives by sulfate radical and subsequent $\mathrm{HO}^{-}$addition. The energies of the various products were computed using both DFT and high-level wavefunction based methods to assess the accuracy of all the computational methods used in the main text. 
(a) Forward $\mathrm{E}_{\mathrm{a}}$ for $\mathrm{HO}^{-}$Addition

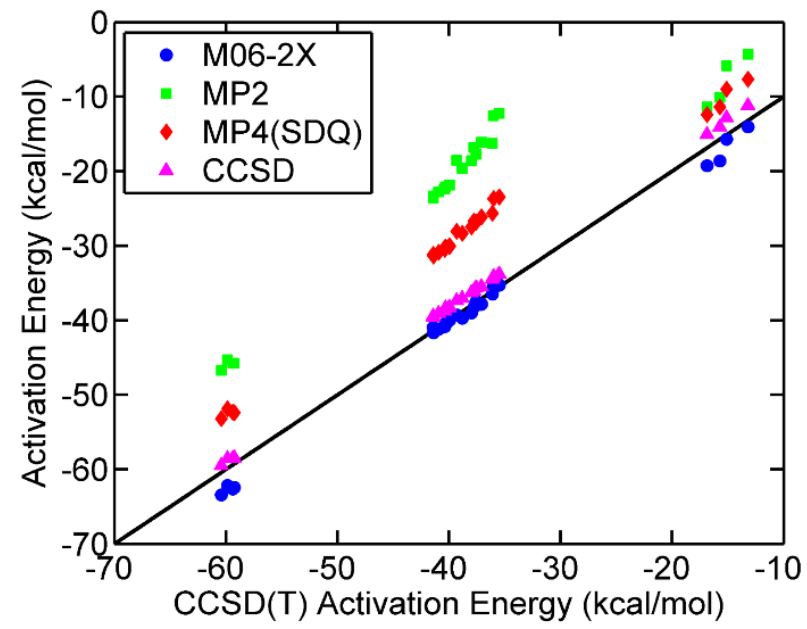

(b) Reverse $\mathrm{E}_{\mathrm{a}}$ for $\mathrm{HO}^{-}$Addition

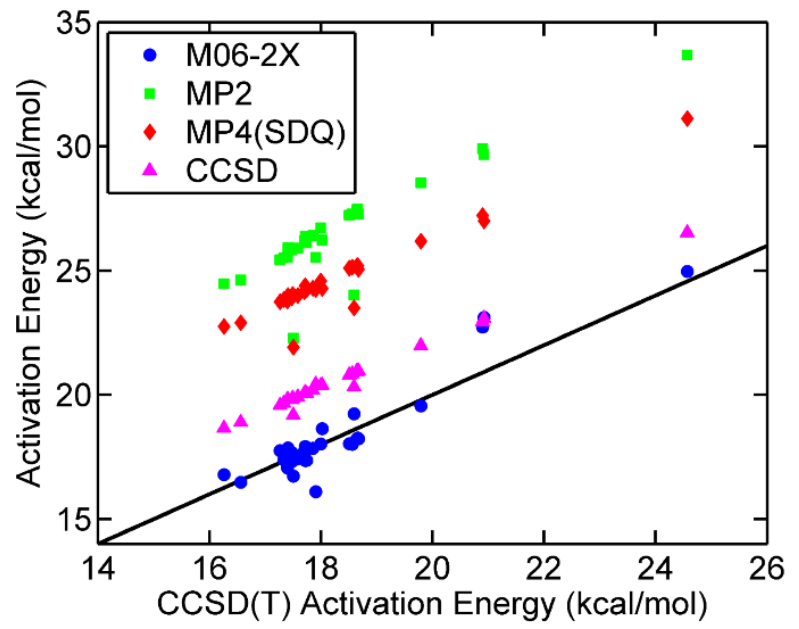

Figure 8. Predicted activation energies of the (a) forward and (b) reverse reactions of benzenederived cation radical reacting with $\mathrm{HO}^{-}$. The diagonal line in each figure represents a perfect match to the benchmark $\operatorname{CCSD}(\mathrm{T})$ activation energies.

In contrast to the statistical trends for the $\mathrm{SO}_{4}{ }^{--}$reaction described previously, we find that the various computational methods more accurately predict the activation energies for the $\mathrm{HO}^{-}$ addition, resulting in lower MAEs in general. In particular, both Table 1 and Fig. 8 actually show that the M06-2X functional outperforms all other methods (even the CCSD method) for both the forward and reverse activation energy for the $\mathrm{HO}^{-}$addition. However, we note that the M06-2X $R^{2}$ values $(=0.88)$ for the reverse reaction are noticeably worse than the corresponding MP4(SDQ) and CCSD wavefunction-based methods. Consequently, these deviations from $R^{2}=1$ indicate a non-systematic error in the M06-2X activation energies for the reverse reaction for the $\mathrm{HO}^{-}$ addition. As before, the MP4(SDQ) and MP2 methods incur larger errors compared to either the CCSD or M06-2X calculations for both the forward and reverse activation energy for the $\mathrm{HO}^{-}$ addition. These errors are due to the perturbative nature of the MP4(SDQ) and MP2 methods which do not capture dynamical correlations effects compared to the accurate $\operatorname{CCSD}(\mathrm{T})$ calculations. Based on our benchmarks on activation energies alone, we find that the popular M06-2X DFT 
functional is significantly more accurate for $\mathrm{HO}^{-}$reactions than for $\mathrm{SO}_{4}{ }^{-}$reactions (although further work is needed on assessing the complete reaction pathways). This stark difference in accuracy is due to the training set used to parameterize the M06-2X functional, which primarily consists of hydrocarbon molecules that do not include other non-carbon based environmental species such as $\mathrm{SO}_{4}{ }^{\circ}$. As a result, while the M06-2X functional yields impressive (nearly $\operatorname{CCSD}(\mathrm{T})$-quality) accuracy for conventional reactions, we recommend the use of high-level quantum calculations to spot-check environmental chemistry reactions that may lie outside the training set of the M06-2X functional, particularly for water oxidation reactions that involve $\mathrm{SO}_{4}{ }^{*}$.

\section{Conclusions}

In conclusion, we have examined a wide set of reactions (110 forward and reverse reactions, in total) that play an important role in sulfate radical-based oxidation processes for water reuse and groundwater remediation. To understand these complex reactions at a fundamental level, we utilized a variety of computational techniques including DFT, MP2/MP4 perturbation theory methods, and high-level coupled cluster CCSD/CCSD(T) approaches. While DFT calculations have started to become commonplace in predicting reaction mechanisms and activation energies in environmental processes, many DFT functionals are highly-parameterized and can fail dramatically for chemical species outside of their training set. As a result, additional high-level methods are essential for spot-checking these results and for iterative feedback between theory and experiment, particularly for accurate calculations of reaction mechanisms in environmental chemistry. Within this comprehensive study, which involves over 100 reactions and 5 different computational methods, we found that the popular M06-2X functional is more accurate for $\mathrm{HO}^{-}$ reactions than for $\mathrm{SO}_{4}{ }^{*}$ - reactions (based on high-level $\mathrm{CCSD}(\mathrm{T})$ calculations used as benchmarks). In general, we find that the M06-2X functional does perform reasonably well for both $\mathrm{HO}^{-}$and 
$\mathrm{SO}_{4}{ }^{--}$reactions; however, we noticed a low degree of statistical correlation for the reverse activation energy barriers in the $\mathrm{HO}^{-}$reactions. As a result, while the M06-2X functional yields impressive (nearly $\operatorname{CCSD}(\mathrm{T})$-quality) accuracy for conventional reactions, high-level benchmarks should be carried out to spot-check reactions that may lie outside the training set of M06-2X (such as reactions that involve $\mathrm{SO}_{4}{ }^{-}$or other inorganic oxidants). These extensive calculations and methodological assessments provide a predictive path towards understanding increasingly more complex reaction mechanisms in environmental processes.

\section{Acknowledgements}

I.AW. acknowledges the National Science Foundation through the Research Experiences for Undergraduates (REU) program (ACI-1452367). H.L. was supported by the National Science Foundation (CHE-1611306). All DFT and wavefunction-based calculations by S.P. and B.M.W were supported by the U.S. Department of Energy, Office of Science, Early Career Research Program under Award No. DE-SC0016269. We acknowledge the National Science Foundation for the use of supercomputing resources through the Extreme Science and Engineering Discovery Environment (XSEDE), Project No. TG- ENG160024. The six reviewers are acknowledged for their helpful and constructive comments. 


\section{References}

1. Bufe, M., What took us so long? Direct potable-water reuse debuts in Texas. Water Environment \& Technology August, 2013.

2. Trenberth, K. E., Changes in precipitation with climate change. Climate Research 2011, 47, 123-138.

3. National Research Council (U.S.). Committee on the Assessment of Water Reuse as an Approach for Meeting Future Water Supply Needs.; National Research Council (U.S.). Committee on the Assessment of Water Reuse as an Approach for Meeting Future Water Supply Needs., Water reuse potential for expanding the nation's water supply through reuse of municipal wastewater. National Academies Press,: Washington, D.C., 2012; pp 1 online resource (xiii, 262 p.).

4. Snyder, S. A. Evaluation of Conventional and Advanced Treatment Processes to Remove Endocrine Disruptors and Pharmaceutically Active Compounds. American Water Works Research Foundation Report.: Denver, CO, 2007.

5. Steffen, M. M.; Zhu, Z.; McKay, R. M. L.; Wilhelm, S. W.; Bullerjahn, G. S., Taxonomic assessment of a toxic cyanobacteria shift in hypereutrophic Grand Lake St. Marys (Ohio, USA). Harmful Algae 2014, 33, 12-18.

6. Stackelberg, P. E.; Furlong, E. T.; Meyer, M. T.; Zaugg, S. D.; Henderson, A. K.; Reissman, D. B., Persistence of pharmaceutical compounds and other organic wastewater contaminants in a conventional drinking-watertreatment plant. Science of the Total Environment 2004, 329, 99113.

7. Mompelat, S.; Le Bot, B.; Thomas, O., Occurrence and fate of pharmaceutical products and by-products, from resource to drinking water. Environment International 2009, 35, 803814.

8. Westerhoff, P.; Yoon, Y.; Snyder, S.; Wert, E., Fate of endocrine-disruptor, pharmaceutical, and personal care product chemicals during simulated drinking water treatment processes. Environmental Science \& Technology 2005, 39, 6649-6663.

9. Kleywegt, S.; Pileggi, V.; Yang, P.; Hao, C. Y.; Zhao, X. M.; Rocks, C.; Thach, S.; Cheung, P.; Whitehead, B., Pharmaceuticals, hormones and bisphenol $A$ in untreated source and finished drinking water in Ontario, Canada - and treatment efficiency. Science of the Total Environment 2011, 409, 1481-1488.

10. Mompelat, S.; Thomas, O.; Le Bot, B., Contamination levels of human pharmaceutical compounds in French surface and drinking water. Journal of Environmental Monitoring 2011, 13, 2929-2939.

11. Valcarcel, Y.; Alonso, S. G.; Rodriguez-Gil, J. L.; Gil, A.; Catala, M., Detection of pharmaceutically active compounds in the rivers and tap water of the Madrid Region (Spain) and potential ecotoxicological risk. Chemosphere 2011, 84, 1336-1348.

12. Benotti, M. J.; Trenholm, R. A.; Vanderford, B. J.; Holady, J. C.; Stanford, B. D.; Snyder, S. A., Pharmaceuticals and Endocrine Disrupting Compounds in US Drinking Water. Environmental Science \& Technology 2009, 43, 597-603.

13. Huerta-Fontela, M.; Galceran, M. T.; Ventura, F., Occurrence and removal of pharmaceuticals and hormones through drinking water treatment. Water Research 2011, 45, 1432-1442. 
14. Raut-Jadhav, S.; Saharan, V. K.; Pinjari, D.; Sonawane, S.; Saini, D.; Pandit, A., Synergetic effect of combination of AOP's (hydrodynamic cavitation and H2O2) on the degradation of neonicotinoid class of insecticide. Journal of Hazardous Materials 2013, 261, 139-147.

15. Saharan, V. K.; Badve, M. P.; Pandit, A. B., Degradation of Reactive Red 120 dye using hydrodynamic cavitation. Chemical Engineering Journal 2011, 178, 100-107.

16. Lee, C.; Sedlak, D. L., A novel homogeneous Fenton-like system with Fe(III)phosphotungstate for oxidation of organic compounds at neutral pH values. Journal of Molecular Catalysis a-Chemical 2009, 311, 1-6.

17. An, J. J.; Zhu, L. H.; Zhang, Y. Y.; Tang, H. Q., Efficient visible light photo-Fenton-like degradation of organic pollutants using in situ surface-modified BiFeO3 as a catalyst. Journal of Environmental Sciences 2013, 25, 1213-1225.

18. Bahnmuller, S.; Loi, C. H.; Linge, K. L.; von Gunten, U.; Canonica, S., Degradation rates of benzotriazoles and benzothiazoles under UV-C irradiation and the advanced oxidation process UV/H2O2. Water Research 2015, 74, 143-154.

19. Moreira, F. C.; Boaventura, R. A. R.; Brillas, E.; Vilar, V. J. P., Remediation of a winery wastewater combining aerobic biological oxidation and electrochemical advanced oxidation processes. Water Research 2015, 75, 95-108.

20. He, X. X.; de la Cruz, A. A.; O'Shea, K. E.; Dionysiou, D. D., Kinetics and mechanisms of cylindrospermopsin destruction by sulfate radical-based advanced oxidation processes. Water Research 2014, 63, 168-178.

21. Antoniou, M. G.; de la Cruz, A. A.; Dionysiou, D. D., Intermediates and Reaction Pathways from the Degradation of Microcystin-LR with Sulfate Radicals. Environmental Science \& Technology 2010, 44, 7238-7244.

22. Liu, H. Z.; Bruton, T. A.; Li, W.; Van Buren, J.; Prasse, C.; Doyle, F. M.; Sedlak, D. L., Oxidation of Benzene by Persulfate in the Presence of Fe(III)- and Mn(IV)-Containing Oxides: Stoichiometric Efficiency and Transformation Products. Environmental Science \& Technology 2016, 50, 890-898.

23. Lutze, H. V.; Bakkour, R.; Kerlin, N.; von Sonntag, C.; Schmidt, T. C., Formation of bromate in sulfate radical based oxidation: Mechanistic aspects and suppression by dissolved organic matter. Water Research 2014, 53, 370-377.

24. Qian, Y. J.; Guo, X.; Zhang, Y. L.; Peng, Y.; Sun, P. Z.; Huang, C. H.; Niu, J. F.; Zhou, X. F.; Crittenden, J. C., Perfluorooctanoic Acid Degradation Using UV-Persulfate Process: Modeling of the Degradation and Chlorate Formation. Environmental Science \& Technology 2016, 50, 772781.

25. Zhang, R. C.; Sun, P. Z.; Boyer, T. H.; Zhao, L.; Huang, C. H., Degradation of Pharmaceuticals and Metabolite in Synthetic Human Urine by UV, UV/H2O2, and UV/PDS. Environmental Science \& Technology 2015, 49, 3056-3066.

26. Yang, Y.; Pignatello, J. J.; Ma, J.; Mitch, W. A., Comparison of Halide Impacts on the Efficiency of Contaminant Degradation by Sulfate and Hydroxyl Radical-Based Advanced Oxidation Processes (AOPs). Environmental Science \& Technology 2014, 48, 2344-2351.

27. Minisci, F.; Citterio, A.; Giordano, C., ELECTRON-TRANSFER PROCESSES PEROXYDISULFATE, A USEFUL AND VERSATILE REAGENT IN ORGANIC-CHEMISTRY. Accounts of Chemical Research 1983, 16, 27-32. 
28. Neta, P.; Madhavan, V.; Zemel, H.; Fessenden, R. W., RATE CONSTANTS AND MECHANISM OF REACTION OF SO4.- WITH AROMATIC-COMPOUNDS. Journal of the American Chemical Society 1977, 99, 163-164.

29. Peyton, G. R., THE FREE-RADICAL CHEMISTRY OF PERSULFATE-BASED TOTAL ORGANICCARBON ANALYZERS. Marine Chemistry 1993, 41, 91-103.

30. Liu, H. Z.; Bruton, T. A.; Doyle, F. M.; Sedlak, D. L., In Situ Chemical Oxidation of Contaminated Groundwater by Persulfate: Decomposition by Fe(III)- and Mn(IV)-Containing Oxides and Aquifer Materials. Environmental Science \& Technology 2014, 48, 10330-10336. 31. Li, W.; Jain, T.; Ishida, K.; Liu, H., A mechanistic understanding of the degradation of trace organic contaminants by UV/hydrogen peroxide, UV/persulfate and UV/free chlorine for water reuse. Environmental Science: Water Research \& Technology 2017.

32. Das, T. N., Reactivity and role of $\mathrm{SO} 5$ center dot- radical in aqueous medium chain oxidation of sulfite to sulfate and atmospheric sulfuric acid generation. Journal of Physical Chemistry A 2001, 105, 9142-9155.

33. Buxton, G. V.; Greenstock, C. L.; Helman, W. P.; Ross, A. B., CRITICAL-REVIEW OF RATE CONSTANTS FOR REACTIONS OF HYDRATED ELECTRONS, HYDROGEN-ATOMS AND HYDROXYL RADICALS (.OH/.O-) IN AQUEOUS-SOLUTION. Journal of Physical and Chemical Reference Data 1988, 17, 513-886.

34. Ben Abdelmelek, S.; Greaves, J.; Ishida, K. P.; Cooper, W. J.; Song, W. H., Removal of Pharmaceutical and Personal Care Products from Reverse Osmosis Retentate Using Advanced Oxidation Processes. Environmental Science \& Technology 2011, 45, 3665-3671.

35. Patton, S.; Li, W.; Couch, K. D.; Mezyk, S. P.; Ishida, K. P.; Liu, H., Impact of the Ultraviolet Photolysis of Monochloramine on 1,4-Dioxane Removal: New Insights into Potable Water Reuse. Environmental Science \& Technology Letters 2017, 4, 26-30.

36. Minakata, D.; Li, K.; Westerhoff, P.; Crittenden, J., Development of a Group Contribution Method To Predict Aqueous Phase Hydroxyl Radical (HO center dot) Reaction Rate Constants. Environmental Science \& Technology 2009, 43, 6220-6227.

37. Naumov, S.; von Sonntag, C., Standard Gibbs Free Energies of Reactions of Ozone with Free Radicals in Aqueous Solution: Quantum-Chemical Calculations. Environmental Science \& Technology 2011, 45, 9195-9204.

38. Minakata, D.; Crittenden, J., Linear Free Energy Relationships between Aqueous phase Hydroxyl Radical Reaction Rate Constants and Free Energy of Activation. Environmental Science \& Technology 2011, 45, 3479-3486.

39. Arnold, W. A.; Oueis, Y.; O'Connor, M.; Rinaman, J. E.; Taggart, M. G.; McCarthy, R. E.; Foster, K. A.; Latch, D. E., QSARs for phenols and phenolates: oxidation potential as a predictor of reaction rate constants with photochemically produced oxidants. Environmental Science: Processes \& Impacts 2017.

40. Trogolo, D.; Mishra, B. K.; Heeb, M. B.; von Gunten, U.; Arey, J. S., Molecular Mechanism of NDMA Formation from N,N-Dimethylsulfamide During Ozonation: Quantum Chemical Insights into a Bromide-Catalyzed Pathway. Environmental Science \& Technology 2015, 49, 4163-4175.

41. Lee, M.; Blum, L.; Schmid, E.; Fenner, K.; von Gunten, U., A computer-based prediction platform for the reaction of ozone with organic compounds in aqueous solution: Kinetics and mechanisms. Environmental Science: Processes \& Impacts 2017. 
42. Becke, A. D., Density-Functional Thermochemistry .3. The Role of Exact Exchange. J Chem Phys 1993, 98, 5648-5652.

43. Becke, A. D., A New Mixing of Hartree-Fock and Local Density-Functional Theories. J Chem Phys 1993, 98, 1372-1377.

44. Medvedev, M. G.; Bushmarinov, I. S.; Sun, J.; Perdew, J. P.; Lyssenko, K. A., Density functional theory is straying from the path toward the exact functional. Science 2017, 355, 4952.

45. Rappoport, D.; Crawford, N. R. M.; Furche, F.; Burke, K., Approximate Density Functionals: Which Should I Choose? In Encyclopedia of Inorganic Chemistry, John Wiley \& Sons, Ltd2006.

46. Zhao, Y.; Truhlar, D. G., The M06 suite of density functionals for main group thermochemistry, thermochemical kinetics, noncovalent interactions, excited states, and transition elements: two new functionals and systematic testing of four M06-class functionals and 12 other functionals. Theor Chem Acc 2008, 120, 215-241.

47. Head-Gordon, M.; Pople, J. A.; Frisch, M. J., MP2 energy evaluation by direct methods. Chem Phys Lett 1988, 153, 503-506.

48. Frisch, M. J.; Head-Gordon, M.; Pople, J. A., A direct MP2 gradient method. Chem Phys Lett 1990, 166, 275-280.

49. Trucks, G. W.; Watts, J. D.; Salter, E. A.; Bartlett, R. J., Analytical MBPT(4) gradients. Chem Phys Lett 1988, 153, 490-495.

50. Trucks, G. W.; Salter, E. A.; Sosa, C.; Bartlett, R. J., Theory and implementation of the MBPT density matrix. An application to one-electron properties. Chem Phys Lett 1988, 147, 359366.

51. Purvis, G. D.; Bartlett, R. J., A FULL COUPLED-CLUSTER SINGLES AND DOUBLES MODEL THE INCLUSION OF DISCONNECTED TRIPLES. Journal of Chemical Physics 1982, 76, 1910-1918. 52. Scuseria, G. E.; Janssen, C. L.; Schaefer, H. F., AN EFFICIENT REFORMULATION OF THE CLOSED-SHELL COUPLED CLUSTER SINGLE AND DOUBLE EXCITATION (CCSD) EQUATIONS. Journal of Chemical Physics 1988, 89, 7382-7387.

53. Pople, J. A.; Head-Gordon, M.; Raghavachari, K., Quadratic configuration interaction. A general technique for determining electron correlation energies. The Journal of Chemical Physics 1987, 87, 5968-5975.

54. Zhao, Y.; Truhlar, D. G., How Well Can New-Generation Density Functionals Describe the Energetics of Bond-Dissociation Reactions Producing Radicals? The Journal of Physical Chemistry A 2008, 112, 1095-1099.

55. Hohenstein, E. G.; Chill, S. T.; Sherrill, C. D., Assessment of the Performance of the M05-2X and M06-2X Exchange-Correlation Functionals for Noncovalent Interactions in Biomolecules. J Chem Theory Comput 2008, 4, 1996-2000.

56. Isiklan, M.; Saeed, M. A.; Pramanik, A.; Wong, B. M.; Fronczek, F. R.; Hossain, M. A., A C3 Symmetric Nitrate Complex with a Thiophene-Based Tripodal Receptor. Crystal Growth \& Design 2011, 11, 959-963.

57. Hossain, M. A.; Saeed, M. A.; Fronczek, F. R.; Wong, B. M.; Dey, K. R.; Mendy, J. S.; Gibson, D., Charge-Assisted Encapsulation of Two Chlorides by a Hexaprotonated Azamacrocycle. Crystal Growth \& Design 2010, 10, 1478-1481. 
58. Saeed, M. A.; Wong, B. M.; Fronczek, F. R.; Venkatraman, R.; Hossain, M. A., Formation of an Amine-Water Cyclic Pentamer: A New Type of Water Cluster in a Polyazacryptand. Crystal Growth \& Design 2010, 10, 1486-1488.

59. Saeed, M. A.; Pramanik, A.; Wong, B. M.; Haque, S. A.; Powell, D. R.; Chand, D. K.; Hossain, M. A., Self-assembly of ordered water tetramers in an encapsulated $\left[\mathrm{Br}\left(\mathrm{H}_{2} \mathrm{O}\right)_{12}\right]^{-}$ complex. Chem Commun 2012, 48, 8631-8633.

60. Møller, C.; Plesset, M. S., Note on an Approximation Treatment for Many-Electron Systems. Physical Review 1934, 46, 618-622.

61. III, G. D. P.; Bartlett, R. J., A full coupled-cluster singles and doubles model: The inclusion of disconnected triples. The Journal of Chemical Physics 1982, 76, 1910-1918.

62. Scuseria, G. E.; Janssen, C. L.; III, H. F. S., An efficient reformulation of the closed-shell coupled cluster single and double excitation (CCSD) equations. The Journal of Chemical Physics 1988, 89, 7382-7387.

63. Fortunelli, A.; Tomasi, J., THE IMPLEMENTATION OF DENSITY-FUNCTIONAL THEORY WITHIN THE POLARIZABLE CONTINUUM MODEL FOR SOLVATION. Chemical Physics Letters 1994, 231, 34-39.

64. Tomasi, J.; Bonaccorsi, R.; Cammi, R.; Delvalle, F. J. O., THEORETICAL CHEMISTRY IN SOLUTION - SOME RESULTS AND PERSPECTIVES OF THE CONTINUUM METHODS AND IN PARTICULAR OF THE POLARIZABLE CONTINUUM MODEL. Theochem-Journal of Molecular Structure 1991, 80, 401-424.

65. Delvalle, F. J. O.; Bonaccorsi, R.; Cammi, R.; Tomasi, J., ELECTRON CORRELATION AND SOLVATION EFFECTS .3. INFLUENCE OF THE BASIS SET AND THE CHEMICAL-COMPOSITION ON THE SOLVATION ENERGY COMPONENTS EVALUATED WITH THE QUANTUM-MECHANICAL POLARIZABLE CONTINUUM MODEL. Theochem-Journal of Molecular Structure 1991, 76, 295312.

66. Delvalle, F. J. O.; Tomasi, J., ELECTRON CORRELATION AND SOLVATION EFFECTS .1. BASIC FORMULATION AND PRELIMINARY ATTEMPT TO INCLUDE THE ELECTRON CORRELATION IN THE QUANTUM-MECHANICAL POLARIZABLE CONTINUUM MODEL SO AS TO STUDY SOLVATION PHENOMENA. Chemical Physics 1991, 150, 139-150.

67. Aguilar, M. A.; Delvalle, F. J. O.; Tomasi, J., ELECTRON CORRELATION AND SOLVATION EFFECTS .2. THE DESCRIPTION OF THE VIBRATIONAL PROPERTIES OF A WATER MOLECULE IN A DIELECTRIC GIVEN BY THE APPLICATION OF THE POLARIZABLE CONTINUUM MODEL WITH INCLUSION OF CORRELATION-EFFECTS. Chemical Physics 1991, 150, 151-161.

68. Wong, B. M.; Raman, S., Thermodynamic calculations for molecules with asymmetric internal rotors - Application to 1,3-butadiene. J Comput Chem 2007, 28, 759-766.

69. Wong, B. M.; Steeves, A. H.; Field, R. W., Electronic signatures of large amplitude motions: Dipole moments of vibrationally excited local-bend and local-stretch states of S-0 acetylene. J Phys Chem B 2006, 110, 18912-18920.

70. Oviedo, M. B.; llawe, N. V.; Wong, B. M., Polarizabilities of $\pi$-Conjugated Chains Revisited: Improved Results from Broken-Symmetry Range-Separated DFT and New CCSD(T) Benchmarks. J Chem Theory Comput 2016, 12, 3593-3602. 
71. Rienstra-Kiracofe, J. C.; Tschumper, G. S.; Schaefer, H. F.; Nandi, S.; Ellison, G. B., Atomic and Molecular Electron Affinities: Photoelectron Experiments and Theoretical Computations.

Chem Rev 2002, 102, 231-282.

72. Frisch, M. J.; Trucks, G. W.; Schlegel, H. B.; Scuseria, G. E.; Robb, M. A.; Cheeseman, J. R.; Scalmani, G.; Barone, V.; Mennucci, B.; Petersson, G. A.; Nakatsuji, H.; Caricato, M.; Li, X.; Hratchian, H. P.; Izmaylov, A. F.; Bloino, J.; Zheng, G.; Sonnenberg, J. L.; Hada, M.; Ehara, M.; Toyota, K.; Fukuda, R.; Hasegawa, J.; Ishida, M.; Nakajima, T.; Honda, Y.; Kitao, O.; Nakai, H.; Vreven, T.; Montgomery Jr., J. A.; Peralta, J. E.; Ogliaro, F.; Bearpark, M. J.; Heyd, J.; Brothers, E. N.; Kudin, K. N.; Staroverov, V. N.; Kobayashi, R.; Normand, J.; Raghavachari, K.; Rendell, A. P.; Burant, J. C.; Iyengar, S. S.; Tomasi, J.; Cossi, M.; Rega, N.; Millam, N. J.; Klene, M.; Knox, J. E.; Cross, J. B.; Bakken, V.; Adamo, C.; Jaramillo, J.; Gomperts, R.; Stratmann, R. E.; Yazyev, O.; Austin, A. J.; Cammi, R.; Pomelli, C.; Ochterski, J. W.; Martin, R. L.; Morokuma, K.; Zakrzewski, V. G.; Voth, G. A.; Salvador, P.; Dannenberg, J. J.; Dapprich, S.; Daniels, A. D.; Farkas, Ö.; Foresman, J. B.; Ortiz, J. V.; Cioslowski, J.; Fox, D. J. Gaussian 09, Gaussian, Inc.: Wallingford, CT, USA, 2009. 